\title{
Non-anthracycline chemotherapy associated with a poor outcome in elderly Egyptian patients with diffuse large B-cell non-Hodgkin lymphoma
}

\author{
Ahmed A. Zeeneldin, Yasser A. Sallam, Ayman A. Gaber, Amgad A. Shaheen \\ Department of Medical Oncology, National Cancer Institute, Cairo University, 12622 Cairo, Egypt.
}

Correspondence to: Dr. Yasser A. Sallam, Department of Medical Oncology, National Cancer Institute, Cairo University, 12622 Cairo, Egypt.

E-mail: ysallam@hotmail.com

\section{A B S T R A C T}

Aim: Rituximab plus cyclophosphamide, doxorubicin, vincristine, and prednisone (CHOP) is the standard treatment for patients with diffuse large B-cell non-Hodgkin lymphoma (DLBCNHL). Nevertheless, anthracyclines are contraindicated for some patients, e.g. cardiac dysfunction, severe hepatic dysfunction, jaundice. Thus, this study assessed the effectiveness of non-anthracycline chemotherapy regimen cyclophosphamide, vincristine, and prednisone (CVP) in elderly DLBCNHL patients vs. the standard CHOP. Methods: This retrospective study included 418 DLBCNHL patients diagnosed between 2003 and 2006 and followed until March 2014. During this period of time, rituximab was not available for all patients, particularly for patients older than 60 years. Results: CHOP and CVP were administered to $351(84 \%)$ and $67(16 \%)$ patients, respectively. Older age and comorbidities, particularly cardiovascular and diabetes mellitus, were independent determinants for not receiving CHOP. Patients received more courses of CHOP treatment than that of CVP $(6$ vs. 3 courses; $P<0.001)$ and developed more toxicities $(48.4 \%$ vs. $23.9 \% ; P<0.001)$, particularly fatigue, alopecia, and gastrointestinal tract toxicities. Complete response rate was higher in CHOP than in CVP $(69.9 \%$ vs. $29.9 \% ; P<0.001)$. Moreover, early death was significantly higher in CVP group of patients than in CHOP $(43.3 \%$ vs. $8.6 \% ; P<0.001)$. After a median follow-up of 71 months, the median overall survival (OS) and event-free survival (EFS) were significantly better in CHOP than in CVP (49.5 vs. 3.7 months and 32.2 vs. 3.5 months; $P<0.001$ for both, respectively). Older age, poor age-adjusted International Prognostic Index scores, not receiving CHOP or consolidative radiotherapy were independent predictors of poor OS and EFS. Conclusion: Use of the CVP regime to treat DLBCNHL patients who were unfit to the standard CHOP treatment was associated with lower remission rates and poorer EFS and OS in this group of patients.

Key words: Non-Hodgkin's lymphoma, diffuse large B-cell, anthracycline, chemotherapy, treatment

\section{Introduction}

Non-Hodgkin's lymphoma (NHL) was the 10th most commonly diagnosed cancer and the 9th cause of cancer mortality in the world in 2012. ${ }^{[1]}$ In Egypt, NHL was the 4th most common cancer in males and 5 th in females and the 5 th cause of cancer mortality. ${ }^{[1,2]}$ NHL is a diverse group of malignancies with different clinical and biological features. ${ }^{[3]}$ Diffuse large B-cell NHL (DLBCNHL) is the most common NHL type in the world, accounting for $30 \%$ of NHL and $80 \%$ of its aggressive subtypes. ${ }^{[4]}$ In Egypt, DLBCNHL accounts for $44.5 \%$ of lymphoid malignancies in a population-based cancer registry ${ }^{[5]}$ and $50 \%$ of NHL subtypes at the Egyptian

\begin{tabular}{|l|l|}
\hline \multicolumn{2}{|c|}{ Access this article online } \\
\hline Quick Response Code: & Website: \\
\hline & www.jcmtjournal.com \\
\cline { 2 - 2 } & \\
\hline
\end{tabular}

National Cancer Institute. ${ }^{[6]}$ DLBCNHL treatment mostly relies on multi-agent combination chemotherapy. ${ }^{[7]}$ The addition of the anti-CD20 monoclonal antibody rituximab to the chemotherapy combination dramatically improved overall survival (OS). ${ }^{[8,9]}$ Anthracyclines, particularly doxorubicin are an integral component of these combination chemotherapy regimens, e.g. cyclophosphamide, doxorubicin, vincristine, prednisone (CHOP); procarbazine, methotrexate, doxorubicin, cyclophosphamide, etoposidecytarabine, bleomycin, vincristine, methotrexate; methotrexate-bleomycin, doxorubicin, cyclophosphamide, vincristine, dexamethasone; methotrexate, doxorubicin, cyclophosphamide, vincristine, dexamethasone, bleomycin, and many others. ${ }^{[10]}$ Intensive chemotherapy with more agents failed to show additional benefit, and the CHOP regimen was concluded to be the best available for patients with intermediate and high-grade NHL, including DLBCNHL. ${ }^{[7]}$ Reductions in dose intensity clearly determine treatment efficacy. ${ }^{[1]}$ However, patients with older age, comorbidities, particularly cardiovascular, and expected higher morbidity and mortality may hinder the use of an anthracycline. ${ }^{[12,13]}$ Compared to 
anthracycline-containing regimens, the 3-year OS is almost halved when a non-anthracycline-containing regimen is used with an absolute survival reduction of $23 \% .^{[12]}$

Thus, the aim of this retrospective study was to investigate the effectiveness of non-anthracycline chemotherapy regimen on elderly DLBCNHL patients by mainly focusing on geriatric organ dysfunction, frailty and comorbidities vs. suboptimal treatment with the cyclophosphamide, vincristine, and prednisone (CVP) vs. the standard CHOP to assess the factors that impact the regimen choice.

\section{Methods}

\section{Study population}

This retrospective clinical study included 418 patients with a confirmed DLBCNHL diagnosis at Tanta Cancer Center, Gharbiah, Egypt between 2003 and 2006. Diagnosis of DLBCNHL was based on histology and immunohistochemical data on CD19, CD20, and CD 22 expression. Patients were treated with either CHOP chemotherapy regimen (cyclophosphamide $750 \mathrm{mg} / \mathrm{m}^{2}$ intravenous (IV) on day 1 , doxorubicin $50 \mathrm{mg} / \mathrm{m}^{2} \mathrm{IV}$ on day 1 , vincristine $1.4 \mathrm{mg} / \mathrm{m}^{2}$ (maximum $2 \mathrm{mg}$ ) IV on day 1 and prednisone $100 \mathrm{mg}$ p.o. for 5 days) or CVP regimen (same as CHOP without doxorubicin) and followed-up until March 2014 via phone conversation. Response to therapy was assessed using the response criteria developed by the lymphoma International Working Group. ${ }^{[14]}$ OS is calculated from the date of diagnosis to the date of death from any cause or last follow-up. Event-free survival (EFS) was calculated from the date of starting treatment to the date of relapse, progression, death or last follows up. ${ }^{[14]}$ Clinicopathological data were extracted from patients' medical records. This study was approved by the Institutional Review Board of the Egyptian National Cancer Institute.

\section{Statistical analyses}

Statistical analyses were performed using IBM SPSS software version 21.0 (SPSS Inc., Chicago, IL, USA). Nominal and categorical variables were compared using the Chi-square or Fisher's exact test. Numerical variables were compared using $t$-test or Man-Whitney's test. Multivariate logistic regression was used to describe the use of CHOP or CVP, controlling for patient covariates. Unadjusted survival was estimated using the Kaplan-Meier method and groups were compared using the log-rank test. Stepwise Cox regression hazards model was used for calculating adjusted survival for each treatment, controlling for patients covariates. A probability $P \leq 0.05$ was considered statistically significant. The primary endpoint was OS. The secondary endpoint included EFS, complete response (CR) rate, and treatment-related toxicities.

\section{Results}

\section{Patients' characteristics}

CHOP and CVP were administered to 351 (84\%) and $67(16 \%)$ patients, respectively. Compared with those receiving CVP, patients receiving CHOP were significantly younger, having less comorbidity, better performance status (PS), fewer B-symptoms, and lower International Prognostic Index-risk (IPI-risk) categories [Table 1]. Logistic regression analysis assessed the impact of different baseline characteristics on the likelihood to receive CHOP or CVP. Only age and comorbidities were independent determinants of the regimen received [Table 2]. Older patients had 10.5 odds of not receiving CHOP compared to the younger patients $(95 \%$ confidence interval $(\mathrm{CI})$ : 4.6-23.6; $P<0.001)$. Patients with comorbidities had 37.2 odds of not receiving CHOP compared to those with no comorbidities (95\% CI: 12.6-109.6; $P<0.001$ ).

Table 1: Characteristics of 418 DLBCNHL patients

\begin{tabular}{|c|c|c|c|c|}
\hline \multirow[t]{2}{*}{ Characteristic } & \multirow[t]{2}{*}{ Subgroup } & \multicolumn{2}{|c|}{$n(\%)$} & \multirow[t]{2}{*}{$P$} \\
\hline & & CHOP & CVP & \\
\hline $\bar{n}$ & & 351 & 67 & \\
\hline \multirow[t]{3}{*}{ Age } & Mean \pm SD & $48.6 \pm 13.3$ & $69.7 \pm 8.8$ & $<0.001$ \\
\hline & $<70$ & $334(95.2)$ & $29(43.3)$ & \\
\hline & $\geq 70$ & $17(4.8)$ & $38(56.7)$ & $<0.001$ \\
\hline \multirow[t]{2}{*}{ LDH } & $\leq$ Normal & $78(22.2)$ & $12(17.9)$ & \\
\hline & $>$ Normal & $273(77.8)$ & $55(82.1)$ & 0.431 \\
\hline \multirow[t]{2}{*}{ Gender } & Female & $176(50.1)$ & $30(44.8)$ & \\
\hline & Male & $175(49.9)$ & $37(55.2)$ & 0.421 \\
\hline \multirow[t]{2}{*}{ Comorbidity } & No & $289(82.3)$ & $4(6.0)$ & \\
\hline & Yes & $62(17.7)$ & $63(94)$ & $<0.001$ \\
\hline \multirow[t]{2}{*}{ Bulky disease } & Yes & $40(11.4)$ & $6(9.0)$ & \\
\hline & No & $311(88.6)$ & $61(91.0)$ & 0.673 \\
\hline \multirow[t]{2}{*}{ PS grouping } & $0-1$ & $221(63.0)$ & $21(31.3)$ & \\
\hline & $2-4$ & $130(37.0)$ & $46(69.7)$ & $<0.001$ \\
\hline \multirow{2}{*}{$\begin{array}{l}\text { Extra-nodal } \\
\text { disease }\end{array}$} & No & $232(66.1)$ & $44(65.7)$ & \\
\hline & Yes & $119(33.9)$ & $23(34.3)$ & 0.946 \\
\hline \multirow[t]{4}{*}{ Stage } & 1 & $68(19.4)$ & $16(23.9)$ & \\
\hline & 2 & $128(36.5)$ & $20(29.9)$ & \\
\hline & 3 & $119(33.9)$ & $23(34.3)$ & \\
\hline & 4 & $36(10.3)$ & $8(11.9)$ & 0.701 \\
\hline \multirow[t]{2}{*}{ B symptoms } & A & $191(54.4)$ & $27(40.3)$ & \\
\hline & $\mathrm{B}$ & $160(45.6)$ & $40(59.7)$ & 0.034 \\
\hline \multirow[t]{4}{*}{ IPI risk category } & Low & $85(24.2)$ & $3(4.5)$ & \\
\hline & $\begin{array}{l}\text { Low } \\
\text { intermediate }\end{array}$ & $150(42.7)$ & $15(22.4)$ & \\
\hline & $\begin{array}{l}\text { High } \\
\text { intermediate }\end{array}$ & $86(24.5)$ & $18(26.9)$ & \\
\hline & High & $30(8.5)$ & $31(46.3)$ & $<0.001$ \\
\hline \multirow[t]{2}{*}{ aaIPI groups } & $0-1$ & $90(25.6)$ & $17(25.4)$ & \\
\hline & $2-3$ & $261(74.4)$ & $50(74.6)$ & 0.963 \\
\hline
\end{tabular}

DLBCNHL: Diffuse large B-cell non-Hodgkin's lymphoma; CHOP: Cyclophosphamide, doxorubicin, vincristine, and prednisone; CVP: Cyclophosphamide, vincristine, and prednisone; SD: Standard deviation; LDH: Lactate dehydrogenase; IPI: International prognostic index; aaIPI: Age-adjusted international prognostic index; PS: Performance status 
Patients with diabetes mellitus, hypertension, and cardiovascular diseases (e.g. myocardial infarction, heart failure, cerebrovascular stroke) were significantly more common in the CVP group [Table 3]. Among different comorbidities, cardiovascular diseases, and diabetes mellitus were the most significant ones that guided regimen selection. The odds of not receiving CHOP were 125 times higher in patients with cardiovascular diseases compared

Table 2: Multivariate analysis of the factors that impact not receiving CHOP treatment

\begin{tabular}{lcc}
\hline Variables in equation & OR $(\mathbf{9 5 \%}$ CI) & $\boldsymbol{P}$ \\
\hline Age $(\geq 60$ vs. $<60$ years $)$ & $10.5(4.6-23.6)$ & $<0.001$ \\
Comorbidity (yes $v s$. no) & $37.2(12.6-109.6)$ & $<0.001$ \\
\hline
\end{tabular}

CHOP: Cyclophosphamide, doxorubicin, vincristine, and prednisone; CI: Confidence interval; OR: Odds ratio

Table 3: Comorbidities among DLBCNHL patients receiving CHOP or CVP

\begin{tabular}{llccc}
\hline Comorbidity & Sub-group & \multicolumn{2}{c}{$\boldsymbol{n}(\%)$} & $P$ \\
\cline { 2 - 3 } & & CHOP & CVP & \\
\hline Diabetes mellitus & No & $330(94.0)$ & $43(64.2)$ & \\
& Yes & $21(6.0)$ & $24(35.8)$ & $<0.001$ \\
Hypertension & No & $345(98.3)$ & $60(89.6)$ & \\
& Yes & $6(1.7)$ & $7(10.4)$ & 0.002 \\
Cardiovascular & No & $340(96.9)$ & $15(22.4)$ & \\
& Yes & $11(3.1)$ & $52(77.6)$ & $<0.001$ \\
Renal impairment & No & $347(98.9)$ & $64(95.5)$ & \\
& Yes & $4(1.1)$ & $3(4.5)$ & 0.085 \\
Liver disease & No & $331(94.3)$ & $64(95.5)$ & \\
& Yes & $20(5.7)$ & $3(4.5)$ & 1.000 \\
Others* & No & $343(97.7)$ & $61(91.0)$ & \\
& Yes & $8(2.3)$ & $6(9.0)$ & 0.014 \\
\hline
\end{tabular}

*Include bronchial asthma, chronic obstructive airway disease, thyroid dysfunction, ulcerative colitis, rheumatoid arthritis, and systemic lupus erythematous. DLBCNHL: Diffuse large B-cell non-Hodgkin's lymphoma; CHOP: Cyclophosphamide, doxorubicin, vincristine, and prednisone; CVP: Cyclophosphamide, vincristine, and prednisone to those without cardiovascular diseases (95\% CI: 48-327; $P<0.001)$. The odds of not receiving CHOP was 9 times higher in patients with diabetes mellitus compared to those without diabetes mellitus (95\% CI: 3-28; $P<0.001$ ).

\section{Treatment responses and toxicities}

Patients with CHOP treatment received more chemotherapy cycles than those treated with CVP (median 6 and 3 cycles, respectively; $P<0.001$; Table 4). $\mathrm{CR}$ rate was higher in CHOP-treated patients than in CVP-treated patients (69.9\% vs. 29.9\%; $P<0.001)$. More patients received radiotherapy after CHOP treatment achieved CR than CVP-treated patients $(22.2 \%$ vs. $3 \% ; P=0.001$; Table 3). Compared to CVP, CHOP was associated with significantly higher toxicities $(48.4 \%$ vs. $23.9 \% ; P<0.001)$, particularly fatigue, alopecia, and gastrointestinal tract toxicities. However, early deaths following one or two chemotherapy courses were significantly higher in patients with CVP treatment than with CHOP treatment (43.3\% vs. 8.6\%; P<0.001).

\section{Overall survival and event-free survival}

The median EFS was 22 months (range: 1.0-104.7 months; 95\% CI: 16.7-27.4 months) in these patients [Figure 1]. The 2- and 5-year EFS rates were $47.8 \%$ and $30.4 \%$, respectively. However, compared to CVP, CHOP was associated with significantly better EFS (median of 32.2 vs. 3.5 months; $P<0.001$ ). After 5 years, no CVP-treated patients were event-free compared to $36 \%$ of CHOP-treated patients [Table 5]. The EFS was also significantly better in patients who were younger than 60 years, females had no comorbidities or B symptoms, good PS, lower stages, or lower IPI scores or those who received consolidative radiotherapy. Multivariate analysis showed that age $>60$ years old, poor age-adjusted IPI (aaIPI) scores, and not receiving CHOP or radiotherapy were independent predictors for poor EFS [Table 6].

The median follow-up period of time was 71 months (range between 1.0 and 111.7 months;

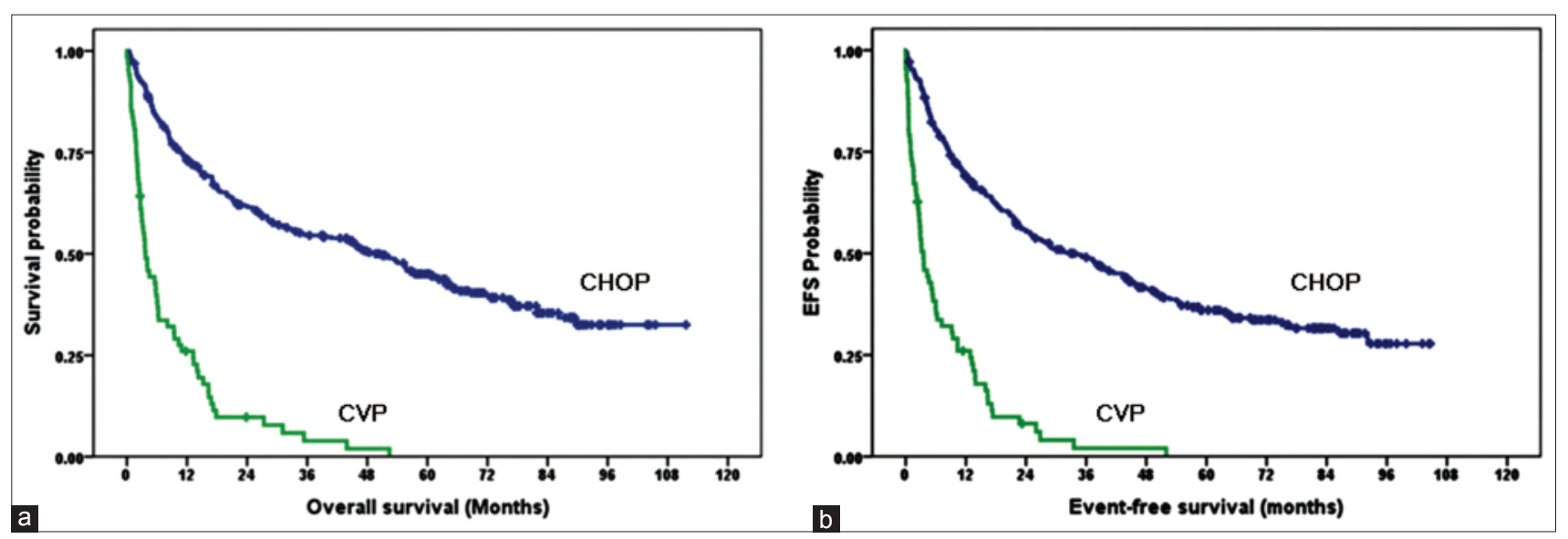

Figure 1: Kaplan-Meier curves of overall survival (OS) and event-free survival stratified by CHOP and CVP regimes. (a) OS of DLBCNHL patients after receiving CHOP or CVP treatment; (b) event-free survival of DLBCNHL patients after receiving CHOP or CVP therapy. CHOP: Cyclophosphamide, doxorubicin, vincristine, and prednisone; DLBCNHL: Diffuse large B-cell non-Hodgkin lymphoma; CVP: Cyclophosphamide, vincristine, and prednisone 
Table 4: First-line treatments administered to DLBCNHL patients according to their age

\begin{tabular}{|c|c|c|c|c|}
\hline \multirow[t]{2}{*}{ Characteristic } & \multirow[t]{2}{*}{ Sub-group } & \multicolumn{2}{|c|}{$n(\%)$} & \multirow[t]{2}{*}{$P$} \\
\hline & & CHOP & CVP & \\
\hline No cycles $1 \mathrm{st}$ & $\begin{array}{l}\text { Median } \\
\text { (range) }\end{array}$ & $6(1-9)$ & $3(1-8)$ & $<0.001$ \\
\hline \multirow[t]{2}{*}{ Toxicity } & No & 181 (51.6) & $51(76.1)$ & \\
\hline & Yes & $170(48.4)$ & $16(23.9)$ & $<0.001$ \\
\hline \multirow[t]{2}{*}{ Early death* } & No & $321(91.4)$ & $38(56.7)$ & \\
\hline & Yes & $30(8.6)$ & $29(43.3)$ & $<0.001$ \\
\hline \multirow[t]{2}{*}{ Fatigue } & No & $230(65.5)$ & $61(91)$ & \\
\hline & Yes & $121(34.5)$ & $6(9)$ & $<0.001$ \\
\hline \multirow[t]{2}{*}{ Alopecia } & No & $230(65.5)$ & $62(92.5)$ & \\
\hline & Yes & $121(34.5)$ & $5(7.5)$ & $<0.001$ \\
\hline \multirow[t]{2}{*}{ Anemia } & No & $333(94.9)$ & $67(100.0)$ & \\
\hline & Yes & $18(5.1)$ & $0(0)$ & 0.092 \\
\hline \multirow[t]{2}{*}{ Neutropenia } & No & $317(90.3)$ & $63(94.0)$ & \\
\hline & Yes & $34(9.7)$ & $4(6.0)$ & 0.486 \\
\hline \multirow[t]{2}{*}{ Thrombocytopenia } & No & $343(97.7)$ & $67(100)$ & \\
\hline & Yes & $8(2.3)$ & $0(0)$ & 0.365 \\
\hline \multirow[t]{2}{*}{$\mathrm{GIT}^{*}$} & No & $319(90.9)$ & $67(100.0)$ & \\
\hline & Yes & $32(9.1)$ & $0(0)$ & 0.005 \\
\hline \multirow[t]{2}{*}{ Skin } & No & $346(98.6)$ & $67(100.0)$ & \\
\hline & Yes & $5(1.4)$ & $0(0)$ & 1.000 \\
\hline \multirow[t]{2}{*}{ DVT } & No & $345(98.3)$ & $67(100.0)$ & \\
\hline & Yes & $6(1.7)$ & $0(0)$ & 0.595 \\
\hline \multirow[t]{2}{*}{ Liver } & No & $345(98.3)$ & $67(100.0)$ & \\
\hline & Yes & $6(1.7)$ & $0(0)$ & 0.595 \\
\hline \multirow[t]{2}{*}{ Response group } & $\mathrm{CR}$ & $245(69.8)$ & $20(29.9)$ & \\
\hline & No CR & $106(30.2)$ & $47(70.1)$ & $<0.001$ \\
\hline \multirow[t]{2}{*}{ Radiotherapy } & No & $273(77.8)$ & $65(97.0)$ & \\
\hline & Yes & $78(22.2)$ & $2(3.0)$ & 0.001 \\
\hline
\end{tabular}

*Early death after 1-2 courses of chemotherapy (response was not assessed). DLBCNHL: Diffuse large B-cell non-Hodgkin's lymphoma; CHOP: Cyclophosphamide, doxorubicin, vincristine, and prednisone; CVP: Cyclophosphamide, vincristine, and prednisone; CR: Complete remission; PR: Partial remission; SD: Stable disease; GIT: Gastrointestinal toxicity in the form of either: mucositis, diarrhea or constipation; DVT: Deep venous thrombosis

95\% CI: 66.3-75.0 months) [Figure 1]. At the last follow-up, 263 patients were deceased (199 in the CHOP group and 64 in the CVP group). The median OS rate was 28.6 (95\% CI: 17.0-40.2) for this cohort of patients. However, the median OS rate was significantly longer in CHOP-treated patients than that of CVP-treated patients (49.5 vs. 3.7 months; $P<0.001$; Table 5). The median OS rate was also significantly longer in young patients without comorbidities, bulky disease or B symptoms, good PS, lower stages, and IPI or aaIPI scores or patients who received consolidation radiotherapy. The multivariate analysis showed that age $>60$ years, poor aaIPI scores, and not receiving CHOP or radiotherapy were independent predictors of poor OS [Table 6].

\section{Discussion}

Since its development in the late 1960's, doxorubicin has been firmly established as the most effective single agent in the treatment of malignant lymphoma. ${ }^{[15,16]}$ The CHOP regime was invented in the late 1970's and after its efficacy in NHL was established, it became the standard of care as it produced high $\mathrm{CR}$ rate and durable effects. ${ }^{[15,17]}$ Its known adverse effects mainly affect the cardiovascular system. ${ }^{[15,16,18]}$ Reduction of inter-treatment intervals (CHOP-14) and the addition of rituximab (R-CHOP) were shown to improve treatment outcomes. ${ }^{[16]}$ CHOP-14 does not appear to be superior to CHOP-21 when given with rituximab, but associates with increased toxicities, including an increased risk of Pneumocystis Jiroveci Pneumonia. Use of R-CHOP-21 is recommended rather than $\mathrm{R}-\mathrm{CHOP}-14$. This is primarily due to decreased need for growth factor support, and a lack of data showing the superiority of one regimen over another in the rituximab era. More intensive chemotherapy or additional agents have failed to show additional benefit. ${ }^{[7]}$ However, elimination of anthracycline from the treatment regimen reduced the $\mathrm{CR}$ rate, duration of response and disease stabilization, and OS. ${ }^{[12,13]}$

In the current study, $16 \%$ of DLBCNHL patients (67/418) did not receive anthracycline, whereas other studies showed a higher percentage (20-67\%) as they only included patients aged 66 years or older. ${ }^{[12,19,20]}$ However, Link et al. ${ }^{[18]}$ reported a lower percentage in an older population. Different studies in the different period of time and inclusion criteria may explain this variance. The rate of anthracycline use in the treatment of DLBCNHL did not vary with time, that is, between the pre-rituximab era and the post-rituximab era. ${ }^{[18]}$ Furthermore, similar to other studies, ${ }^{[18,19,21]}$ our current study showed that older age and comorbidities were strong indictors of treatment regimen selection without doxorubicin in addition to cardiovascular diseases and diabetes mellitus but the lower relevance of kidney and liver disease. ${ }^{[19]}$ Pre-therapy heart disease, diabetes, hypertension, and older age were reported to be independent predictors of cardiotoxicity and subsequent death from the same cause. ${ }^{[22-24]}$ Our results also concur with those of van de Schans et al. ${ }^{[25]}$ and Peters et al. ${ }^{[26]}$ regarding the impact of poor PS and estimated short survival on the likelihood of treatment regimens without anthracycline. We showed that early death, that is, following 1-2 chemotherapy courses was encountered more in the non-anthracycline group (43.3\% vs. 8.6\%). Expected higher toxicities are another important reason. While this is difficult to assess quantitatively before therapy is given, it was confirmed by the higher rates of toxicities in the CHOP compared to the CVP group (48.4\% vs. 23.9\%).

The lower response rate with the CVP regimen without anthracycline than anthracycline-containing CHOP regimen confirms the established fact that anthracycline is the most active single agent in the treatment of lymphoma. ${ }^{[12,13,15,16]}$ In the current study, doxorubicin contributed almost $40 \%$ of the CRs exceeding the 
Table 5: EFS and OS of 418 DLBCNHL patients

\begin{tabular}{|c|c|c|c|c|c|c|c|c|c|}
\hline \multirow[t]{2}{*}{ Group } & \multirow[t]{2}{*}{$n$} & \multicolumn{4}{|c|}{ EFS } & \multicolumn{4}{|c|}{$\overline{\mathrm{OS}}$} \\
\hline & & Median & 2-year rate & 5-year rate & $P$ & Median & 2-year rate & 5-year rate & $P$ \\
\hline$\overline{\text { All }}$ & 418 & 22.0 & 47.8 & 30.4 & & 28.6 & 53.3 & 37.9 & \\
\hline \multicolumn{10}{|c|}{ First line chemotherapy } \\
\hline CHOP & 351 & 32.2 & 55.3 & 36.0 & & 49.5 & 61.8 & 45.0 & \\
\hline CVP & 67 & 3.5 & 8.1 & 0 & $<0.001$ & 3.7 & 9.7 & 0 & $<0.001$ \\
\hline \multicolumn{10}{|l|}{ Age (years) } \\
\hline$<60$ & 297 & 39.4 & 59.6 & 39.9 & & 57.4 & 67.0 & 49.6 & \\
\hline$\geq 60$ & 121 & 6.3 & 18.2 & 5.7 & $<0.001$ & 6.0 & 19.0 & 6.3 & $<0.001$ \\
\hline \multicolumn{10}{|l|}{ Gender } \\
\hline Male & 212 & 17.8 & 43.6 & 25.0 & & 25.0 & 50.0 & 35.6 & \\
\hline Female & 206 & 26.8 & 52.2 & 35.9 & 0.032 & 43.0 & 56.7 & 40.3 & 0.188 \\
\hline \multicolumn{10}{|l|}{ Comorbidities } \\
\hline No & 293 & 35.2 & 56.0 & 36.2 & & 53.7 & 63.3 & 46.4 & \\
\hline Yes & 125 & 7.2 & 28.4 & 16.4 & $<0.001$ & 8.0 & 28.8 & 16.7 & $<0.001$ \\
\hline \multicolumn{10}{|l|}{ Bulky disease } \\
\hline Yes & 46 & 13.9 & 34.8 & 24.6 & & 17.0 & 43.5 & 31.2 & \\
\hline No & 372 & 23.9 & 49.5 & 31.1 & 0.178 & 31.1 & 54.6 & 38.8 & 0.407 \\
\hline \multicolumn{10}{|l|}{ B symptoms } \\
\hline A & 218 & 28.8 & 54.7 & 36.4 & & 46.2 & 60.0 & 42.8 & \\
\hline B & 200 & 16.0 & 40.2 & 32.6 & 0.002 & 18.0 & 45.8 & 32.6 & 0.003 \\
\hline \multicolumn{10}{|l|}{ PS } \\
\hline $0-1$ & 242 & 41.2 & 59.7 & 38.6 & & 55.9 & 67.0 & 48.8 & \\
\hline $2-4$ & 176 & 9.7 & 31.2 & 18.9 & $<0.001$ & 10.6 & 34.2 & 22.7 & $<0.001$ \\
\hline \multicolumn{10}{|l|}{ Extra-nodal } \\
\hline No & 276 & 22.9 & 48.8 & 29.7 & & 31.1 & 55.2 & 38.4 & \\
\hline Yes & 142 & 18.0 & 45.8 & 31.8 & 0.738 & 21.8 & 49.5 & 37.1 & 0.376 \\
\hline \multicolumn{10}{|l|}{ Stage } \\
\hline 1.0 & 84 & 76.7 & 63.0 & 52.2 & & NR & 68.1 & 5.6 & \\
\hline 2.0 & 148 & 20.6 & 45.3 & 29.2 & & 28.0 & 52.4 & 36.8 & \\
\hline 3.0 & 142 & 19.1 & 44.4 & 21.3 & & 25.6 & 50.3 & 32.8 & \\
\hline 4.0 & 44 & 6.9 & 39.5 & 19.1 & $<0.001$ & 8.8 & 41.9 & 21.9 & $<0.001$ \\
\hline \multicolumn{10}{|l|}{ Stage-group } \\
\hline $1-2$ & 232 & 26.0 & 51.6 & 37.4 & & 44.2 & 57.3 & 43.4 & \\
\hline $3-4$ & 186 & 16.3 & 43.2 & 20.7 & 0.001 & 21.3 & 48.3 & 30.7 & 0.006 \\
\hline \multicolumn{10}{|l|}{ IPI-group } \\
\hline Low & 88 & NR & 72.0 & 57.6 & & NR & 79.1 & 65.4 & \\
\hline Low intermediate & 165 & 28.9 & 54.1 & 31.3 & & 45.6 & 62.3 & 42.2 & \\
\hline High intermediate & 104 & 14.1 & 39.3 & 21.3 & & 16.3 & 42.5 & 27.2 & \\
\hline High & 61 & 4.6 & 9.2 & 0 & $<0.001$ & 4.6 & 10.7 & 0 & $<0.001$ \\
\hline \multicolumn{10}{|l|}{ aaIPI } \\
\hline $0-1$ & 107 & 52.0 & 62.4 & 84.2 & & NR & 68.3 & 54.7 & \\
\hline $2-3$ & 311 & 17.8 & 42.8 & 24.1 & $<0.001$ & 20.5 & 46.5 & 32.1 & $<0.001$ \\
\hline \multicolumn{10}{|l|}{ Radiotherapy } \\
\hline No & 338 & 17.2 & 43.5 & 26.6 & & 20.0 & 47.9 & 32.9 & \\
\hline Yes & 80 & 50.7 & 66.1 & 46.0 & $<0.001$ & 72.5 & 77.5 & 58.8 & $<0.001$ \\
\hline
\end{tabular}

EFS: Event-free survival; OS: Overall survival; DLBCNHL: Diffuse large B-cell non-Hodgkin's lymphoma; CHOP: Cyclophosphamide, doxorubicin, vincristine, and prednisone; CVP: Cyclophosphamide, vincristine, and prednisone; PS: Performance status; IPI: International prognostic index; aaIPI: Age adjusted international prognostic index; NR: Not reached

combination of cyclophosphamide, vincristine, and prednisolone (from $29.9 \%$ to $69.9 \%$ ) in DLBCNHL treated solely by chemotherapy. Achieving $\mathrm{CR}$ is crucial for long-term survival and cure. ${ }^{[27]}$ Our current study clearly shows that patients are failing to achieve CR only had a median OS of 4.4 months compared to 76.8 months in those who achieved CR with almost 11-fold higher relative risk of death. CHOP-produced $\mathrm{CR}$ rates is comparable to those reported by Khaled et al., ${ }^{[28]}$ Burton et al., ${ }^{[29]}$ Hallack Neto et al. ${ }^{[30]}$ [Table 7]. However, a large Egyptian study by Abdelhamid et al. ${ }^{[6]}$ reported a $10 \%$ higher $\mathrm{CR}$ rate. This latter study only included younger patients with a maximum age of 60 , better PS, and lower aaIPI scores. In contrast, our current 
study included older patients with a maximum age of 82 , poorer PS, and higher aaIPI scores. Patients that are older and have poor PS frequently received reduced doses or interrupted and delayed therapy. This reduced dose intensity is a key determinant of CR and survival. ${ }^{[6,31]}$

In the current study, removal of the anthracycline doxorubicin from the $\mathrm{CHOP}$ regimen significantly reduced the median OS (unadjusted from 49.5 to 3.7 months, i.e. 45.8 months and adjusted from 44 to 9 months, i.e. 35 months) and the 3-year OS (unadjusted from $54.5 \%$ to $3.9 \%$ i.e. $50.5 \%$ and adjusted from $52 \%$ to $19 \%$ i.e. $33 \%$ ) with an increase in the hazards of death by 4 times. This is similar to Tien et $a l^{[12]}$ and Link et al. ${ }^{[18]}$ who showed a $22 \%$ and $16 \%$ decline in 3 -year OS, respectively [Table 7]. The difference in our study $(33 \%)$ may be due to the poorer outcome of patients

Table 6: Multivariate analysis of EFS and OS in DLBCNHL patients

\begin{tabular}{|c|c|c|c|c|}
\hline \multirow{2}{*}{$\begin{array}{l}\text { Variables in } \\
\text { equation }\end{array}$} & \multicolumn{2}{|l|}{ EFS } & \multicolumn{2}{|l|}{ OS } \\
\hline & HR $(95 \%$ CI) & $P$ & HR (95\% CI) & $P$ \\
\hline $\begin{array}{l}\text { Age }(\geq 60 v s . \\
<60 \text { years })\end{array}$ & $2.1(1.6-2.9)$ & $<0.001$ & $2.5(1.8-3.0)$ & $<0.001$ \\
\hline $\begin{array}{l}\text { First line } \\
\text { chemotherapy } \\
\text { (non-CHOP } \\
\text { vs. CHOP) }\end{array}$ & $2.6(1.9-3.7)$ & $<0.001$ & $2.6(1.8-3.8)$ & $<0.001$ \\
\hline $\begin{array}{l}\text { aaIPI (score } \\
0-1 \text { vs. 2-3) }\end{array}$ & $1.8(1.3-2.5)$ & $<0.001$ & $2.0(1.4-2.7)$ & $<0.001$ \\
\hline $\begin{array}{l}\text { Radiotherapy } \\
\text { (no vs. yes) }\end{array}$ & $1.8(1.3-2.5)$ & $<0.001$ & $2.1(1.5-3.1)$ & $<0.001$ \\
\hline
\end{tabular}

DLBCNHL: Diffuse large B-cell non-Hodgkin's lymphoma; CHOP: Cyclophosphamide, doxorubicin, vincristine, and prednisone; CVP: Cyclophosphamide, vincristine, and prednisone; EFS: Event-free survival; OS: Overall survival; HR: Hazard's ratio; CI: Confidence interval; aaIPI: Age-adjusted international prognostic index; IPI: International prognostic index receiving non-anthracycline-containing regimens (19\%) compared to that in the mentioned studies $(29 \%$ and $33 \%$ ). This may be due to the more developed health care system in the US than Egypt as the former ranks 37 th and the latter ranks 63th in overall health system performance. $^{[33]}$ A high performing health care system is capable of providing better supportive therapies for patients that are elderly, having comorbidities and progressing on inadequate anti-lymphoma therapy.

OS with CHOP treatment $(52 \%$ at 3 years) in the current study is comparable to the $49-57 \%$ figure reported by many authors [Table 7], ${ }^{[6,9,12,18]}$ but was lower than the $60-70 \%$ OS reported by Habermann et al., ${ }^{[32]}$ Burton et al., ${ }^{[29]}$ and Khaled et al. ${ }^{[28]}$ All of these studies performed prospective trials where patients were carefully selected and generally fit to tolerate therapy. It is understandable that results from phase III studies do not always translate into corresponding outcomes in the general population. ${ }^{[18]}$

Similar to CR and OS, our current data showed that removal of doxorubicin from the CHOP regimen significantly reduced EFS. We could not easily find information on the use of CVP in DLBCNHL to compare our EFS with the studies that comparison of anthracycline-containing regimens to non-anthracycline-containing regimens only showed OS. ${ }^{[12,18]}$ The EFS rate of CHOP treatment in our current study is similar to Sehn et al. ${ }^{[9]}$ and Habermann et $a l .{ }^{[32]}$ However, it was lower than that of Khaled et al. ${ }^{[28]}$ and Burton et al. ${ }^{[29]}$ This may be explained by the difference in study settings between the well-controlled environment of a clinical trial and the community practice environment. The disease-free survival of our study $(75.9 \%$ at 2 years) was similar to that of Abdelhamid et al. ${ }^{[6]}$ (68.8\%) who used a similar setting to our study. It was higher than that reported by Hallack Neto et al. ${ }^{[30]}$ This retrospective Brazilian study reported on a relatively small number of

Table 7: Comparison of treatment outcomes in DLBCNHL patients

\begin{tabular}{|c|c|c|c|c|c|c|}
\hline Authors & Regimen & $n$ & Age & CR (\%) & 2-year (3-year) EFS/PFS (\%) & 2-year (3-year) OS (\%) \\
\hline \multirow[t]{2}{*}{ Our current study } & $\mathrm{CHOP}$ & 251 & $17-82$ & 69.8 & $55.3(46.0)$ & $58.0(52.0)$ \\
\hline & CVP & 67 & $45-87$ & $29.9 *$ & $18.0(12.0)^{*}$ & $25.0(19.0)^{*}$ \\
\hline \multirow[t]{2}{*}{ Tien et al. ${ }^{[12]}$} & $\mathrm{ACR}$ & 1090 & $\geq 66$ & & & $(52)$ \\
\hline & Non-ACR & 267 & $\geq 66$ & & & $(29)^{*}$ \\
\hline \multirow[t]{2}{*}{ Link et al. ${ }^{[18]}$} & ACR & 2346 & $\geq 66$ & & & $59(49)$ \\
\hline & Non-ACR & 460 & $\geq 66$ & & & $40(33)^{*}$ \\
\hline Abdelhamid et al. ${ }^{[6]}$ & $\mathrm{CHOP}$ & 224 & $18-60$ & 79.5 & 2-year DFS: 68.8 & $57(57)$ \\
\hline Hallack Neto et al. ${ }^{[30]}$ & CHOP & 77 & $<60$ & 68.8 & 2-year DFS: 61.3 & 5-year OS: 72.8 \\
\hline Habermann et al. ${ }^{[32]}$ & CHOP & 279 & $>60$ & & (46) & $(60)$ \\
\hline Sehn et al..$^{[9]}$ & ACR & 140 & $19-86$ & & $51 \%(46 \%)$ & $52(50)$ \\
\hline Khaled et al. ${ }^{[28]}$ & $\mathrm{CHOP}$ & 40 & $19-75$ & 67 & $54(54)$ & $82(71)$ \\
\hline \multirow[t]{2}{*}{ Burton et al. ${ }^{[29]}$} & $\mathrm{CHOP}$ & 105 & $22-66$ & 70 & 4-year PFS: 56 & 4-year OS: 65 \\
\hline & CIOP & 106 & $25-67$ & 52 & 4-year PFS: 40* & 4-year OS: $56^{\#}$ \\
\hline
\end{tabular}

${ }^{*} P<0.05,{ }^{*} P \geq 0.05$. EFS: Event-free survival; PFS: Progression-free survival; DFS: Disease-free survival; CHOP: Cyclophosphamide, doxorubicin, vincristine, and prednisone; CVP: Cyclophosphamide, vincristine, and prednisone; ACR: Anthracycline containing regimen; CIOP: Cyclophosphamide, idarubicin, vincristine, and prednisone; CR: Complete response; DLBCNHL: Diffuse large B-cell non-Hodgkin's lymphoma 
patients $(n=77)$ with many poorer prognostic factors than ours.

DLBCNHL is potentially curable after treated with anthracycline-containing regimens; however, a significant proportion of patients do not receive anthracyclines, particularly doxorubicin for various reasons, e.g. older age, expected poor tolerance or significant comorbidities. These patients present an unmet medical need. ${ }^{[12]}$ Measures that may decrease toxicity and improve anthracycline tolerance includes adequate supports (e.g. hematopoietic growth factors), dose reductions, increase in infusion time, the addition of cardio-protectants (e.g. dexrazoxane). ${ }^{[16,18,26,34,35]}$ An alternative less-toxic and more tolerable anthracycline may be considered if feasible, e.g. liposomal doxorubicin, ${ }^{[36,37]}$ epirubicin, ${ }^{[38]}$ mitoxantrone ${ }^{[39]}$ or pixantrone. ${ }^{[40]}$ In case an anthracycline cannot be used, substitution with other agents, e.g. etoposide or gemcitabine may better than omission. ${ }^{[41]}$ Addition of the immunotherapy agent like rituximab to non-anthracycline-containing regimens significantly improves the outcomes and should be considered. ${ }^{[18]}$ Non-anthracycline-containing regimens with the addition of rituximab produced equivalent outcomes to anthracycline-containing regimens. ${ }^{[12,18,19]}$

\section{References}

1. Bray F, Ren JS, Masuyer E, Ferlay J. Global estimates of cancer prevalence for 27 sites in the adult population in 2008 . Int $J$ Cancer 2013;132:1133-45.

2. Ibrahim AS, Khaled HM, Mikhail NN, Baraka H, Kamel H. Cancer incidence in egypt: results of the national population-based cancer registry program. J Cancer Epidemiol 2014;2014:437971.

3. Boffetta P. Epidemiology of adult non-Hodgkin lymphoma. Ann Oncol 2011;22 Suppl 4:iv27-31.

4. Swerdlow SH, Campo E, Harris NL, Jaffe ES, Pileri SA, Stein $\mathrm{H}$, Thiele J, Vardiman JW. WHO Classification of Tumours of Haematopoietic and Lymphoid Tissue. 4th ed. Geneva: World Health Organization; 2008.

5. Herzog CM, Dey S, Hablas A, Khaled HM, Seifeldin IA, Ramadan M, El-Hamzawy H, Wilson ML, Soliman AS. Geographic distribution of hematopoietic cancers in the Nile delta of Egypt. Ann Oncol 2012;23:2748-55.

6. Abdelhamid T, Samra M, Ramadan H, Mehessin M, Mokhtar N. Clinical prognostic factors of diffuse large B cell non-Hodgkin lymphoma: a retrospective study. J Egypt Natl Canc Inst 2011;23:17-24.

7. Fisher RI, Gaynor ER, Dahlberg S, Oken MM, Grogan TM, Mize EM, Glick JH, Coltman CA Jr, Miller TP. Comparison of a standard regimen (CHOP) with three intensive chemotherapy regimens for advanced non-Hodgkin's lymphoma. $N$ Engl $J$ Med 1993;328:1002-6.

8. Coiffier B, Thieblemont C, Van Den Neste E, Lepeu G, Plantier I, Castaigne S, Lefort S, Marit G, Macro M, Sebban C, Belhadj K, Bordessoule D, Fermé C, Tilly H. Long-term outcome of patients in the LNH-98.5 trial, the first randomized study comparing rituximab-CHOP to standard CHOP chemotherapy in DLBCL patients: a study by the Groupe d'Etudes des Lymphomes de l'Adulte. Blood 2010;116:2040-5.
9. Sehn LH, Donaldson J, Chhanabhai M, Fitzgerald C, Gill K, Klasa R, MacPherson N, O’Reilly S, Spinelli JJ, Sutherland J, Wilson KS, Gascoyne RD, Connors JM. Introduction of combined CHOP plus rituximab therapy dramatically improved outcome of diffuse large B-cell lymphoma in British Columbia. J Clin Oncol 2005;23:5027-33.

10. Armitage JO. The place of third-generation regimens in the treatment of adult aggressive non-Hodgkin's lymphoma. Ann Oncol 1991;2 Suppl 1:37-41.

11. Dixon DO, Neilan B, Jones SE, Lipschitz DA, Miller TP, Grozea PN, Wilson HE. Effect of age on therapeutic outcome in advanced diffuse histiocytic lymphoma: the Southwest Oncology Group experience. J Clin Oncol 1986;4:295-305.

12. Tien YY, Link BK, Brooks JM, Wright K, Chrischilles E. Treatment of diffuse large B-cell lymphoma in the elderly: regimens without anthracyclines are common and not futile. Leuk Lymphoma 2015;56:65-71.

13. Bastion Y, Blay JY, Divine M, Brice P, Bordessoule D, Sebban C, Blanc M, Tilly H, Lederlin P, Deconinck E, Salles B, Dumontet C, Brière J, Coiffier B. Elderly patients with aggressive non-Hodgkin's lymphoma: disease presentation, response to treatment, and survival - a Groupe d'Etude des Lymphomes de l'Adulte study on 453 patients older than 69 years. J Clin Oncol 1997;15:2945-53.

14. Cheson BD, Horning SJ, Coiffier B, Shipp MA, Fisher RI, Connors JM, Lister TA, Vose J, Grillo-López A, Hagenbeek A, Cabanillas F, Klippensten D, Hiddemann W, Castellino R, Harris NL, Armitage JO, Carter W, Hoppe R, Canellos GP. Report of an International Workshop to Standardize Response Criteria for Non-Hodgkin's Lymphomas. NCI Sponsored International Working Group. J Clin Oncol 1999;17:1244.

15. Gottlieb JA, Gutterman JU, McCredie KB, Rodriguez V, Frei E 3rd. Chemotherapy of malignant lymphoma with adriamycin. Cancer Res 1973;33:3024-8.

16. Luminari S, Montanini A, Federico M. Anthracyclines: a cornerstone in the management of non-Hodgkin's lymphoma. Hematol Rep 2011;3:e4.

17. Armitage JO, Fyfe MA, Lewis J. Long-term remission durability and functional status of patients treated for diffuse histiocytic lymphoma with the CHOP regimen. J Clin Oncol 1984;2:898-902.

18. Link BK, Brooks J, Wright $\mathrm{K}$, Pan X, Voelker M, Chrischilles E. Diffuse large B-cell lymphoma in the elderly: diffusion of treatment with rituximab and survival advances with and without anthracyclines. Leuk Lymphoma 2011;52:994-1002.

19. Grann VR, Hershman D, Jacobson JS, Tsai WY, Wang J, McBride R, Mitra N, Grossbard ML, Neugut AI. Outcomes and diffusion of doxorubicin-based chemotherapy among elderly patients with aggressive non-Hodgkin lymphoma. Cancer 2006;107:1530-41.

20. Keating NL, Landrum MB, Lamont EB, Bozeman SR, Krasnow SH, Shulman LN, Brown JR, Earle CC, Oh WK, Rabin M, McNeil BJ. Quality of care for older patients with cancer in the Veterans Health Administration versus the private sector: a cohort study. Ann Intern Med 2011;154:727-36.

21. Picozzi VJ, Pohlman BL, Morrison VA, Lawless GD, Lee MW, Kerr RO, Ford JM, Delgado DJ, Fridman M, Carter WB. Patterns of chemotherapy administration in patients with intermediate-grade non-Hodgkin's lymphoma. Oncology (Williston Park) 2001;15:1296-306.

22. Jurczak W, Szmit S, Sobocinski M, Machaczka M, Drozd-Sokolowska J, Joks M, Dzietczenia J, Wróbel T, Kumiega B, Zaucha JM, Knopińska-Posłuszny W, Spychałowicz W, Prochwicz A, Drohomirecka A, 
Skotnicki AB. Premature cardiovascular mortality in lymphoma patients treated with (R)-CHOP regimen - a national multicenter study. Int $J$ Cardiol 2013;168:5212-7.

23. Hortobágyi GN. Anthracyclines in the treatment of cancer. An overview. Drugs 1997;54 Suppl 4:1-7.

24. Hershman DL, McBride RB, Eisenberger A, Tsai WY, Grann VR, Jacobson JS. Doxorubicin, cardiac risk factors, and cardiac toxicity in elderly patients with diffuse B-cell non-Hodgkin's lymphoma. J Clin Oncol 2008;26:3159-65.

25. van de Schans SA, Wymenga AN, van Spronsen DJ, Schouten HC, Coebergh JW, Janssen-Heijnen ML. Two sides of the medallion: Poor treatment tolerance but better survival by standard chemotherapy in elderly patients with advanced-stage diffuse large B-cell lymphoma. Ann Oncol 2012;23:1280-6.

26. Peters FP, Fickers MM, Erdkamp FL, Wals J, Wils JA, Schouten HC. The effect of optimal treatment on elderly patients with aggressive non-Hodgkin's lymphoma: more patients treated with unaffected response rates. Ann Hematol 2001;80:406-10.

27. Nicolaides C, Dimou S, Pavlidisa N. Prognostic factors in aggressive non-Hodgkin's lymphomas. Oncologist 1998;3:189-97.

28. Khaled HM, Zekri ZK, Mokhtar N, Ali NM, Darwish T, Elattar I, Gaafar R, Moawad MS. A randomized EPOCH vs. CHOP front-line therapy for aggressive non-Hodgkin's lymphoma patients: long-term results. Ann Oncol 1999;10:1489-92.

29. Burton C, Smith P, Vaughan-Hudson G, Qian W, Hoskin P, Cunningham D, Hancock $\mathrm{B}$, Linch $\mathrm{D}$. Comparison of CHOP versus CIOP in good prognosis younger patients with histologically aggressive non-Hodgkin lymphoma. $\mathrm{Br} J$ Haematol 2005;130:536-41.

30. Hallack Neto AE, Pereira J, Beitler B, Chamone DA, Llacer PD, Dulley FL, Chaoubah A. Results of CHOP chemotherapy for diffuse large B-cell lymphoma. Braz J Med Biol Res 2006;39:1315-22.

31. Lyman GH, Dale DC, Friedberg J, Crawford J, Fisher RI. Incidence and predictors of low chemotherapy dose-intensity in aggressive non-Hodgkin's lymphoma: a nationwide study. $J$ Clin Oncol 2004;22:4302-11.

32. Habermann TM, Weller EA, Morrison VA, Gascoyne RD, Cassileth PA, Cohn JB, Dakhil SR, Woda B, Fisher RI, Peterson BA, Horning SJ. Rituximab-CHOP versus CHOP alone or with maintenance rituximab in older patients with diffuse large B-cell lymphoma. J Clin Oncol 2006;24:3121-7.

33. World Health Organization Assesses the World's Health Systems. World Health Report; 2000. Available from: http:// www.who.int/whr/2000/media_centre/press_release/en/.
[Last accessed on 2015 Apr 27].

34. Gisselbrecht C, Haioun C, Lepage E, Bastion Y, Tilly H, Bosly A, Dupriez B, Marit G, Herbrecht R, Deconinck E, Marolleau JP, Yver A, Dabouz-Harrouche F, Coiffier B, Reyes F. Placebo-controlled phase III study of lenograstim (glycosylated recombinant human granulocyte colony-stimulating factor) in aggressive non-Hodgkin's lymphoma: factors influencing chemotherapy administration. Groupe d'Etude des Lymphomes de l'Adulte. Leuk Lymphoma 1997;25:289-300.

35. Amadori D. Moving forward with new data and approaches: a fresh look at anthracyclines in non-Hodgkin's lymphoma. Hematol Rep 2011;3:e1.

36. Schmitt CJ, Dietrich S, Ho AD, Witzens-Harig M. Replacement of conventional doxorubicin by pegylated liposomal doxorubicin is a safe and effective alternative in the treatment of non-Hodgkin's lymphoma patients with cardiac risk factors. Ann Hematol 2012;91:391-7.

37. Visani G, Isidori A. Nonpegylated liposomal doxorubicin in the treatment of B-cell non-Hodgkin's lymphoma: where we stand. Expert Rev Anticancer Ther 2009;9:357-63.

38. Lambertenghi Deliliers G, Butti C, Baldini L, Ceriani A, Lombardi F, Luoni M, Montalbetti L, Pavia G, Pinotti G, Pogliani E, Vanoli P. A cooperative study of epirubicin with cyclophosphamide, vincristine and prednisone (CEOP) in non-Hodgkin's lymphoma. Haematologica 1995;80:318-24.

39. Vose JM, Weisenburger DD, Lynch JC, Bierman PJ, Chan JC, Bast M, Aoun P, Bociek G, Greiner T, Armitage JO; Nebraska Lymphomas Study Group. CNOP for diffuse aggressive non-Hodgkin's lymphoma: the Nebraska lymphoma study group experience. Leuk Lymphoma 2002;43:799-804.

40. Mukherji D, Pettengell R. Pixantrone maleate for non-Hodgkin's lymphoma. Drugs Today (Barc) 2009;45:797-805.

41. Fields PA, Townsend W, Webb A, Counsell N, Pocock C, Smith P, Jack A, El-Mehidi N, Johnson PW, Radford J, Linch DC, Cunnningham D. De novo treatment of diffuse large B-cell lymphoma with rituximab, cyclophosphamide, vincristine, gemcitabine, and prednisolone in patients with cardiac comorbidity: a United Kingdom National Cancer Research Institute trial. J Clin Oncol 2014;32:282-7.

How to cite this article: Zeeneldin AA, Sallam YA, Gaber AA, Shaheen AA. Non-anthracycline chemotherapy associated with a poor outcome in elderly Egyptian patients with diffuse large B-cell non-Hodgkin lymphoma. J Cancer Metastasis Treat 2015;1:76-83.

Received: 02-11-2014; Accepted: 08-04-2015.

Source of Support: Nil, Conflict of Interest: None declared. 